\title{
Desenvolvimento de mudas de cultivares de café arábica enxertadas sobre Apoatã IAC 2258
}

\section{Development of seedlings of arabica cvs. grafted in Apoatã IAC 2258}

\author{
Fabio Pereira Dias ${ }^{1}$; Alex Mendonça de Carvalho ${ }^{2 *}$; \\ Antonio Nazareno Guimarães Mendes ${ }^{3}$; Haroldo Silva Vallone ${ }^{4}$; \\ Andre Dominghetti Ferreira ${ }^{5}$; Juliana Costa de Rezende ${ }^{2}$
}

Resumo

O objetivo foi avaliar o desenvolvimento de mudas de diferentes cultivares de Coffea arabica enxertadas sobre a cultivar Apoatã IAC 2258 (Coffea canephora). O experimento foi conduzido em esquema fatorial 7 x $3+2$, composto por sete cultivares de C. arabica (Obatã IAC 1669-20, Acauã, Oeiras MG 6851, Catucaí Amarelo 2SL, Topázio MG 1190, IBC Palma II e Paraíso MG H 419-1), três tipos de mudas (enxertada, auto-enxertada e pé franco) e duas testemunhas (porta-enxerto Apoatã IAC 2258 auto-enxertado e pé franco). O delineamento experimental foi o de blocos casualizados com quatro repetições. Foram avaliadas as características altura de plantas, área foliar, massa seca da parte aérea e do sistema radicular. As mudas pé franco apresentaram maiores valores das características avaliadas em comparação as mudas enxertadas. Os efeitos da auto-enxertia e da enxertia de C. arabica sobre 'Apoatã IAC 2258' varia em função do genótipo enxertado. A cultivar IBC Palma II possui comportamento indiferente ao tipo de muda à qual é produzida para a característica altura. Existe diferença de comportamento do sistema radicular do porta enxerto em função da cultivar utilizada como enxerto. As combinações 'Apoatã IAC 2258' com os enxertos Obatã IAC 1669-20, Acauã ou Oeiras MG 6851 podem ser indicadas para utilização em áreas infestadas por nematoide.

Palavras-chave: Coffea arabica, C. canephora, crescimento vegetativo, raiz, mudas

\begin{abstract}
This study evaluated the development of seedlings of Coffea arabica cvs. grafted in Apoatã IAC 2258 (Coffea canephora). The experimental design used was a randomized block with a $7 \times 3+2$ factorial arrangement. Were utilized seven C. arabica cultivars (Obatã IAC 1669-20, Acauã, Oeiras MG 6851, Catucaí Amarelo 2SL, Topázio MG 1190, IBC Palma II and Paraíso MG H 419-1), three kinds of seedlings (grafted, self grafted and ungrafted) and two Apoatã IAC 2258 rootstocks control (ungrafted and self grafted). There were evaluated the plant height, leaf area, aerial parts dry matter and root system dry matter. The ungrafted seedling showed the best development for all the evaluated characteristics. The effects of ungrafted and self grafted varies depending on the genotype grafted. The IBC Palma II cv. has behavior indifferent to the type of change which is produced for the trait height. There is a difference in behavior of the root system of the rootstock depending on the cultivar used as a graft. The grafts Obatã IAC 1669-20, Acauã or Oeiras MG 6851 can be recommend for use in areas infested with nematodes.
\end{abstract}

Key words: Coffea arabica, C. canephora, vegetative growth, root, seedling

${ }^{1}$ Prof. do Instituto Federal Minas Gerais, Bambuí , MG. E-mail: fabio.dias@ifmg.edu.br

2 Pós doutorando em Fitotecnia, Universidade Federal de Lavras, UFLA/CNPq, Lavras, MG. E-mail: carvalho.am@hotmail.com; julianacr@epamig.ufla.br

3 Prof. do Dept ${ }^{\circ}$ de Agricultura, UFLA, Lavras, MG. E-mail: naza@dag.ufla.br

${ }^{4}$ Prof. do Instituto Federal Triângulo Mineiro, Campus Uberaba, MG. E-mail: haroldo@iftriangulo.edu.br

5 Pesquisador da Empresa Brasileira de Pesquisa Agropecuária, EMBRAPA, Campo Grande, MS. E-mail: andre.dominghetti@ embrapa.br

* Autor para correspondência 


\section{Introdução}

Dentre os fatores limitantes ao processo de crescimento e produção do cafeeiro, destacam-se os fitonematoides, microorganismos de solo capazes de parasitar o sistema radicular da planta durante praticamente todo o ciclo da cultura no campo. Nos últimos anos, extensivos levantamentos e estudos têm detectado um vasto número de espécies de nematóides capazes de parasitar as raízes de cafeeiro (CARNEIRO et al., 2008, MUNIZ et al., 2008) e a situação pode diferir grandemente de uma região para outra.

Diante da vasta ocorrência de Meloidogyne exigua em lavouras cafeeiras dos Pais (CASTRO et al., 2008, OLIVEIRA et al., 2005) e dos riscos da sua disseminação, a utilização da enxertia de cafeeiros da espécie Coffea arabica L. em porta enxertos tolerantes aos fitonematoides têm viabilizado o cultivo desta espécie em áreas infestadas, sendo uma alternativa ao uso do controle químico, cuja utilização é onerosa e com elevado risco de intoxicação humana.

Além da resistência de determinados portaenxertos aos fitonematóides, alguns autores destacam um maior desenvolvimento do sistema radicular e da parte aérea e maior eficiência na absorção de nutrientes da solução do solo, em relação às plantas não enxertadas, podendo essas plantas ser utilizadas também em áreas isentas de nematóides, aumentando com isso o potencial de produção da lavoura (ALFONSI et al., 2005; DIAS et al., 2008; FERREIRA et al., 2010).

O efeito da enxertia pode variar com o material genético utilizado nas diversas combinações enxerto/porta-enxerto. Assim, torna-se importante conhecer o efeito da combinação de enxerto/porta enxerto de genótipos que potencialmente possam ser utilizados como porta-enxerto para Coffea arabica. Dessa forma, conhecer os efeitos do processo de enxertia, onde o porta-enxerto possa aumentar a adaptabilidade da planta enxertada, é de grande relevância para a cafeicultura.
A análise de crescimento tem sido usada na tentativa de explicar diferenças no crescimento, seja de ordem genética, seja resultante de modificações do ambiente e constitui uma ferramenta muito eficiente para a identificação de materiais promissores (FERREIRA et al., 2009).

Dessa forma, este trabalho teve como objetivo avaliar o desenvolvimento de mudas de diferentes cultivares de Coffea arabica enxertadas sobre Coffea canephora 'Apoatã IAC 2258'.

\section{Material e Métodos}

O experimento foi instalado no viveiro de produção de mudas do Setor de Cafeicultura, do Departamento de Agricultura da UFLA, e conduzido por um período de 120 dias, em esquema fatorial 7 × $3+2$, composto por sete cultivares de C. arabica (Obatã IAC 1669-20, Acauã, Oeiras MG 6851, Catucaí Amarelo 2SL, Topázio MG 1190, IBC Palma II e Paraíso MG H 419-1), três tipos de mudas (enxertada, auto-enxertada e pé franco) e duas testemunhas (porta-enxerto Apoatã IAC 2258 auto-enxertado e pé franco). A auto-enxertia foi realizada com o objetivo de isolar o efeito do estresse causado pelo processo de enxertia no porta enxerto Apoatã IAC 2258. O delineamento experimental utilizado foi blocos casualizados (DBC) com quatro repetições

Sementes do porta-enxerto Apoatã IAC 2258 e das cultivares estudadas foram semeadas em caixa de areia lavada. Quando as plântulas atingiram o estádio de "palito-de-fósforo" foram realizadas as enxertias pelo método hipocotiledonar, e a seguir, foram transplantadas para tubetes de polietileno de $120 \mathrm{~cm}^{3}$. Foi utilizado o substrato constituído por $65 \%$ de casca de arroz carbonizada mais $35 \%$ de substrato comercial Plantimax ${ }^{\circledR}$ (VALLONE et al., 2010) adicionado do fertilizante de liberação lenta Osmocote ${ }^{\circledR}$, de formulação $15-10-10$ de NPK mais micronutrientes. 
Os tubetes foram mantidos em câmara de nebulização cobertas com sombrite de cor preta e $75 \%$ de passagem de luz, por um período de 12 dias para facilitar a sobrevivência das mudas. Após este período, as mudas foram colocadas em um canteiro suspenso. A cobertura foi feita com sombrite de cor preta, com passagem de $50 \%$ da luz, e as irrigações foram feitas uma vez ao dia, utilizando sistema automatizado, procurando fornecer 4,5 $\mathrm{mm}$ de água por dia, até as mudas lançarem o $3^{\circ}$ par de folhas, quando foram avaliadas.

As características avaliadas foram: altura das plantas $(\mathrm{cm})$, medida do colo até o meristema apical do ramo ortotrópico; área foliar $\left(\mathrm{cm}^{2}\right.$ planta $\left.{ }^{-1}\right)$; massa seca do sistema radicular; massa seca da parte aérea (g parcela $\left.{ }^{-1}\right)$, em gramas por parcela de cinco plantas. A massa seca da partes aérea e do sistema radicular foram determinados após secagem em estufa com circulação forçada de ar a temperatura de $60^{\circ} \mathrm{C}$ até atingirem massa constante.

As análises estatísticas foram realizadas utilizando os programas computacionais Sisvar (FERREIRA, 2011) e SAS (1997), sendo o primeiro utilizado para a aplicação do teste de médias e o segundo programa utilizado para realizar os contrastes. Foi verificada a significância ao nível de $5 \%$ de probabilidade pelo teste F. Detectando diferenças significativas entre os tratamentos e entre as interações, foram feitos os desdobramentos e as médias foram comparadas entre si pelo teste de Tukey, ao nível de 5\% de probabilidade. As comparações entre os tratamentos do fatorial e os adicionais foram analisadas pelo teste de Dunnett, ao nível de $5 \%$ de probabilidade. Nesse caso, foi estudada apenas a característica massa seca do sistema radicular, considerada adequada para avaliar o efeito da enxertia e das diferentes copas utilizadas e apenas os tratamentos com o mesmo sistema radicular.

\section{Resultados e Discussão}

Houve efeito significativo da interação cultivares $\mathrm{x}$ tipos de muda para todas as características, indicando existir dependência entre os efeitos dos fatores (Tabela 1). No desdobramento de tipos de muda dentro de cada cultivar, o tipo de muda promoveu diferença em todas as características avaliadas (Tabela 2). Em relação a altura da planta, apenas a cultivar IBC Palma II apresentou o mesmo comportamento nos três tipos de muda e, para todas as demais cultivares, a muda enxertada apresentou altura inferior ou igual estatisticamente à muda de pé franco. No caso das cultivares Acauã, Catucaí Amarelo 2 SL, Topázio MG 1190, Paraíso MG H 419-1 e na média geral, a muda auto enxertada também apresentou menor altura que em pé franco, indicando provável efeito negativo causado pelo procedimento da enxertia.

De maneira semelhante, a muda enxertada apresentou menor área foliar em relação à muda de pé franco para todas as cultivares avaliadas. $\mathrm{Na}$ média geral, observa-se redução da área foliar das mudas auto-enxertadas e enxertadas de $24,7 \%$ e $31,4 \%$, respectivamente, comparadas com as de pé franco.

A massa seca do sistema radicular sofreu influência do tipo de muda em todas as cultivares, em que a muda de pé franco apresentou maior massa seca da raiz que as mudas auto-enxertadas e enxertadas. Da mesma forma, o material enxertado e auto-enxertado não se diferiu estatisticamente, indicando que o processo de enxertia causou estresse no desenvolvimento da característica. Avaliando a média geral e a diferença percentual da muda de pé franco comparada com os outros tipos de muda, observa-se que ela produziu $38,4 \%$ e $34,6 \%$ mais massa seca de raiz que a muda enxertada e autoenxertada, respectivamente. 
Tabela 1. Resumo das análises de variância, coeficientes de variação e médias gerais para altura de planta (ALT); área foliar (ARF); massa seca do sistema radicular (MSR), massa seca da parte aérea (MPA).

\begin{tabular}{|c|c|c|c|c|c|}
\hline \multirow[b]{2}{*}{ Fonte de variação } & \multirow[b]{2}{*}{ GL } & \multicolumn{4}{|c|}{ Quadrados médios } \\
\hline & & ALT $(\mathrm{cm})$ & $\operatorname{ARF}\left(\mathrm{cm}^{2}\right)$ & $\operatorname{MSR}(\mathrm{g})$ & MPA (g) \\
\hline Repetição & 3 & $1,572 *$ & 357,224 & $314,604 *$ & 265,151 \\
\hline Cultivares & 6 & 0,980 & $446,66^{* *}$ & $782,810 * *$ & $810,772 * *$ \\
\hline Tipos de muda & 2 & $20,818 * *$ & $10046,509 * *$ & $421,942 * *$ & $883,341 * *$ \\
\hline Cultivares $\mathrm{x}$ tipos muda & 12 & $3,374 * *$ & $1165,131 * *$ & $163,864 * *$ & $167,414^{* *}$ \\
\hline Erro & 60 & 0,458 & 134,042 & 100,740 & 112,942 \\
\hline CV (\%) & & 6,33 & 10,27 & 17,34 & 10,30 \\
\hline Média geral & & 10,69 & 112,73 & 1,830 & 3,26 \\
\hline
\end{tabular}

*; ** Significativo, a $5 \%$ e $1 \%$ de probabilidade, respectivamente, pelo teste $\mathrm{F}$.

Fonte: Elaboração dos autores.

Tabela 2. Valores médios de altura, área foliar de mudas, massa seca do sistema radicular e massa seca da parte aérea de cafeeiro, de sete cultivares e três tipos de mudas.

\begin{tabular}{ccccccccc}
\hline Tipo de & Obatã & Acauã & Oeiras & Catucaí & Topázio & Palma & Paraíso & Média \\
\cline { 2 - 8 } Muda & \multicolumn{7}{c}{ Altura $(\mathrm{cm})$} \\
\hline Enxertada & $10,2 \mathrm{~b}$ & $9,1 \mathrm{c}$ & $10,9 \mathrm{ab}$ & $9,4 \mathrm{c}$ & $9,2 \mathrm{~b}$ & $10,4 \mathrm{a}$ & $9,1 \mathrm{~b}$ & $9,8 \mathrm{c}$ \\
Auto-enx. & $11,2 \mathrm{a}$ & $10,4 \mathrm{~b}$ & $11,9 \mathrm{a}$ & $10,8 \mathrm{~b}$ & $10,3 \mathrm{~b}$ & $10,8 \mathrm{a}$ & $10,2 \mathrm{~b}$ & $10,8 \mathrm{~b}$ \\
Pé Franco & $11,9 \mathrm{a}$ & $11,9 \mathrm{a}$ & $10,5 \mathrm{~b}$ & $12,5 \mathrm{a}$ & $12,3 \mathrm{a}$ & $11,4 \mathrm{a}$ & $11,8 \mathrm{a}$ & $11,8 \mathrm{a}$ \\
\hline Média & $11,1 \mathrm{~A}$ & $10,5 \mathrm{~A}$ & $11,1 \mathrm{~A}$ & $10,9 \mathrm{~A}$ & $10,6 \mathrm{~A}$ & $10,9 \mathrm{~A}$ & $10,4 \mathrm{~A}$ \\
\hline \multicolumn{7}{c}{ Área Foliar $(\mathrm{cm})$} \\
\hline Enxertada & $115,3 \mathrm{~b}$ & $103,0 \mathrm{~b}$ & $109,7 \mathrm{~b}$ & $83,8 \mathrm{~b}$ & $81,5 \mathrm{c}$ & $102,9 \mathrm{~b}$ & $85,5 \mathrm{~b}$ & $97,4 \mathrm{c}$ \\
Auto-enx. & $115,5 \mathrm{~b}$ & $115,0 \mathrm{~b}$ & $114,1 \mathrm{~b}$ & $91,6 \mathrm{~b}$ & $108,7 \mathrm{~b}$ & $99,8 \mathrm{~b}$ & $103,5 \mathrm{~b}$ & $106,9 \mathrm{~b}$ \\
Pé Franco & $142,6 \mathrm{a}$ & $142,6 \mathrm{a}$ & $148,2 \mathrm{a}$ & $145,0 \mathrm{a}$ & $145,0 \mathrm{a}$ & $133,3 \mathrm{a}$ & $137,6 \mathrm{a}$ & $142,0 \mathrm{a}$ \\
\hline Média & $124,5 \mathrm{~A}$ & $120,2 \mathrm{AB}$ & $122,1 \mathrm{~A}$ & $107,8 \mathrm{AB}$ & $111,7 \mathrm{AB}$ & $112,0 \mathrm{AB}$ & $108,9 \mathrm{AB}$ \\
\hline \multicolumn{7}{c}{ Massa seca do sistema radicular $(\mathrm{g} /$ parcela de cinco plantas $)$} \\
\hline Enxertada & $2,0 \mathrm{~b}$ & $1,6 \mathrm{~b}$ & $1,7 \mathrm{~b}$ & $1,2 \mathrm{~b}$ & $1,4 \mathrm{~b}$ & $1,5 \mathrm{~b}$ & $1,4 \mathrm{~b}$ & $1,6 \mathrm{~b}$ \\
Auto-enx. & $1,9 \mathrm{~b}$ & $2,0 \mathrm{~b}$ & $1,7 \mathrm{~b}$ & $1,0 \mathrm{~b}$ & $1,6 \mathrm{~b}$ & $1,5 \mathrm{~b}$ & $1,7 \mathrm{~b}$ & $1,7 \mathrm{~b}$ \\
Pé Franco & $2,7 \mathrm{a}$ & $2,8 \mathrm{a}$ & $2,6 \mathrm{a}$ & $2,6 \mathrm{a}$ & $2,6 \mathrm{a}$ & $2,4 \mathrm{a}$ & $2,2 \mathrm{a}$ & $2,5 \mathrm{a}$ \\
\hline Média & $2,2 \mathrm{~A}$ & $2,1 \mathrm{~A}$ & $2,1 \mathrm{~A}$ & $1,6 \mathrm{~B}$ & $1,9 \mathrm{AB}$ & $1,8 \mathrm{AB}$ & $1,8 \mathrm{AB}$ \\
\hline \multicolumn{7}{c}{ Massa seca da parte aérea $(\mathrm{g} /$ parcela de cinco plantas $)$} \\
\hline Enxertada & $3,4 \mathrm{~b}$ & $2,8 \mathrm{c}$ & $3,2 \mathrm{~b}$ & $2,2 \mathrm{~b}$ & $2,3 \mathrm{c}$ & $2,9 \mathrm{~b}$ & $2,4 \mathrm{c}$ & $2,8 \mathrm{c}$ \\
Auto enx. & $3,5 \mathrm{~b}$ & $3,5 \mathrm{~b}$ & $3,3 \mathrm{~b}$ & $2,5 \mathrm{~b}$ & $3,1 \mathrm{~b}$ & $2,9 \mathrm{~b}$ & $3,0 \mathrm{~b}$ & $3,1 \mathrm{~b}$ \\
Pé Franco & $4,3 \mathrm{a}$ & $4,4 \mathrm{a}$ & $4,4 \mathrm{a}$ & $4,3 \mathrm{a}$ & $3,8 \mathrm{a}$ & $3,9 \mathrm{a}$ & $4,0 \mathrm{a}$ & $4,2 \mathrm{a}$ \\
\hline Média & $3,7 \mathrm{~A}$ & $3,6 \mathrm{AB}$ & $3,7 \mathrm{~A}$ & $3,0 \mathrm{C}$ & $3,2 \mathrm{BC}$ & $3,2 \mathrm{BC}$ & $3,2 \mathrm{BC}$ \\
\hline
\end{tabular}

Médias seguidas de mesma letra na vertical não diferem entre si, pelo teste de Tukey, a 5\% de probabilidade.

Fonte: Elaboração dos autores.

As mudas de pé franco de todas as cultivares apresentaram maiores massa seca da parte aérea que as mudas auto-enxertadas e enxertadas. $\mathrm{O}$ efeito negativo do processo de enxertia (estresse) e do porta-enxerto é variável conforme a cultivar. De forma geral, as mudas enxertadas e a auto- enxertadas apresentaram massa seca da parte aérea $33,3 \%$ e $26,2 \%$ menor que a muda de pé franco, respectivamente.

O menor desenvolvimento das plantas enxertadas, observado no presente trabalho, pode estar associado ao efeito do estresse provocado 
pela prática da enxertia (OLIVEIRA et al., 2004) ou por incompatibilidade entre enxertos e portaenxertos utilizados. Esta incompatibilidade pode ser anatômica (estrutural), em função de diferenças anatômicas entre as duas espécies, dificultando o ajuste entre os tecidos; nutricional, em função de que uma espécie pode apresentar padrão de absorção de água e nutrientes em quantidade e composição que não seja adequado à outra espécie; ou bioquímica, devido à presença de alguma substância em uma das espécies, que interfira no comportamento da outra (DIAS et al., 2008). De acordo com Tomaz et al. (2005), a enxertia em café é capaz de influenciar positiva ou negativamente o desenvolvimento das plantas quando se comparam diferentes combinações enxerto/porta-enxerto com os respectivos pés-francos.

Esse comportamento foi verificado por outros autores. Tomaz et al. (2003) e Figueiredo et al. (2002) estudando mudas de cafeeiro enxertadas ou não no porta-enxertoApoatãIAC2258emmeiohidropônico, verificaram que algumas cultivares enxertadas apresentaram maior altura quando comparadas com seus respectivos pé franco. Entretanto, a maioria das mudas enxertadas apresentou menor altura, indicando que os comportamentos das cultivares não são coincidentes. Em condições isentas de nematóides, Fahl e Carelli (1985) observaram que plantas jovens de $C$. arabica, enxertadas sobre $C$. canephora, apresentaram maior altura de plantas e área foliar. Oliveira et al. (2004), avaliando o desenvolvimento do sistema radicular de cafeeiros enxertados, observaram que as mudas de pé franco desenvolveram mais que as mudas enxertadas em
Apoatã IAC 2258. Guimarães et al. (2003) relatam maior desenvolvimento vegetativo da parte aérea das mudas de pé franco que as enxertadas em Apoatã IAC 2258, independentemente da cultivar de $C$. arabica L. utilizada como enxerto.

De maneira geral, a cultivar IBC Palma II foi a única que apresentou mesma altura quando enxertada, pé franco e auto-enxertada. Esses resultados confirmam a hipótese já citada de estresse provocado pela enxertia. Possivelmente, a diferença detectada se deu em função das variações genéticas das cultivares e morfológicas e fisiológicas do sistema radicular de cada cultivar (TOMAZ et al., 2008; DIAS et al., 2009).

A utilização dos tratamentos adicionais teve como objetivo comparar o desenvolvimento do porta-enxerto quando em pé-franco e auto-enxertado e do porta-enxerto quando auto-enxertado com os tratamentos onde ocorreu a enxertia das cultivares de $C$. arabica no Apoatã IAC 2258. Pela Tabela 3 verifica-se que houve diferenças significativas entre os tratamentos Apoatã IAC 2258 auto-enxertado e Apoatã IAC 2258 pé franco, indicando mais uma vez que, na fase de muda, o processo da enxertia limita o desenvolvimento da planta, em decorrência do estresse. Esses resultados estão de acordo com Dias et al. (2008) e Paiva et al. (2012), os quais afirmam que plantas de C. canephora Pierre, apesar de apresentam um sistema radicular mais desenvolvido, não mantêm essa característica quando são utilizadas como porta-enxerto, não justificando a utilização do porta-enxerto Apoatã IAC 2258, em áreas isentas de nematóides. 
Tabela 3. Comparação do tratamento Apoatã IAC 2258 auto-enxertado com os demais tratamentos para matéria seca do sistema radicular de mudas de cafeeiro (MSR), em gramas por parcela, na interação fatorial versus adicionais.

\begin{tabular}{lcc}
\hline \multicolumn{1}{c}{ Cultivar } & Tipos de mudas & MSR (g) \\
\hline Apoatã IAC 2258 & Auto-enxertada & 0,90 \\
vs. Apoatã IAC 2258 & Pé franco & $1,41^{*}$ \\
& & \\
Apoatã IAC 2258 & Auto-enxertada & 0,90 \\
vs. Obatã IAC 1669-20 & Enxertada & $2,06 *$ \\
vs. Acauã & Enxertada & $1,62^{*}$ \\
vs. Oeiras MG 6851 & Enxertada & $1,77^{*}$ \\
vs. Catucaí Amarelo 2SL & Enxertada & $1,19^{\text {ns }}$ \\
vs. Topázio MG 1190 & Enxertada & $1,38^{\text {ns }}$ \\
vs. IBC Palma II & Enxertada & $1,50^{\text {ns }}$ \\
vs. Paraíso MG H 419-1 & Enxertada & $1,38^{\text {ns }}$ \\
\hline
\end{tabular}

* e ns; contrastes significativos e não significativos, respectivamente, pelo teste de Dunnett a 5\%.

Fonte: Elaboração dos autores.

Os efeitos do porta-enxerto não são passíveis de serem detectados sem se considerar o sistema como um todo (copa/porta-enxerto), uma vez que existe ação recíproca entre as partes envolvidas (PAULETTO et al., 2001; TOMAZ et al., 2008). Dessa forma, na comparação entre Apoatã IAC 2258 auto-enxertado com os tratamentos em que as mudas foram enxertadas sobre esse porta enxerto, foi possível analisar a influência da copa sobre o desempenho do porta-enxerto. As cultivares Obatã IAC 1669-20, Acauã e Oeiras MG 6851 apresentaram maior desenvolvimento do sistema radicular, indicando que existe diferença de comportamento do sistema radicular do portaenxerto em função da cultivar utilizada como enxerto. Estes resultados diferem dos encontrados por Ferreira et al. (2011), os quais verificaram que apenas as cultivares Catucaí 2SL e Paraíso MG H419-1 proporcionaram desenvolvimento do sistema radicular semelhante estatisticamente ao Apoatã auto-enxertado, e que as demais cultivares utilizadas no experimento causaram uma redução no desenvolvimento do sistema radicular.

Vale ressaltar que as características altura, área foliar, massa seca do sistema radicular e da parte aérea têm importância suplementar. Sendo assim, para selecionar uma determinada combinação de variedade-copa com espécie porta-enxerto, devemse observar aquelas combinações que apresentem excelente desenvolvimento vegetativo de mudas, e que demonstrem afinidade na enxertia. Dessa forma, as combinações 'Apoatã IAC 2258' com os enxertos Obatã IAC 1669-20, Acauã ou Oeiras MG 6851 podem ser indicadas para utilização em áreas infestadas por nematoide.

\section{Conclusões}

As mudas pé franco apresentaram melhor desenvolvimento das características avaliadas em comparação as mudas enxertadas.

Os efeitos da auto-enxertia e da enxertia de $C$. arabica sobre 'Apoatã IAC 2258' varia em função do genótipo enxertado.

A cultivar IBC Palma II possui comportamento indiferente ao tipo de muda à qual é produzida para a característica altura.

Existe diferença de comportamento do sistema radicular do porta enxerto em função da cultivar utilizada como enxerto.

As combinações 'Apoatã IAC 2258' com os enxertos Obatã IAC 1669-20, Acauã ou Oeiras MG 6851 podem ser indicadas para utilização em áreas infestadas por nematoide. 


\section{Agradecimentos}

Os autores agradecem à Fundação de Amparo à Pesquisa do Estado de Minas Gerais (FAPEMIG), ao INCT-Café (Instituto Nacional de Ciência e Tecnologia do Café) e ao Consórcio de Pesquisa Café pelo apoio financeiro ao projeto e ao CNPq pela concessão das bolsas PNPD (AMC e JCR).

\section{Referências}

ALFONSI, E. L.; FAHL, J. I.; CARELLI, M. L. C.; FAZUOLI, L. C. Crescimento, fotossíntese e composição mineral em genótipos de Coffea com potencial para utilização como porta-enxerto. Bragantia, Campinas, v. 64, n. 1, p. 1-13, 2005.

CARNEIRO, R. M. D. G.; MESQUITA, L. F.G. de; GONCALVES, W.; PEREIRA, A. A. Pathogenicity of Meloidogyne spp. (Tylenchida: Meloidogynidae) from Brazil and Central America on two genotypes of Coffea arabica. Tropical Plant Pathology, Brasilia, v. 33, n. 4, p. 309-312, 2008.

CASTRO, J. M. C.; CAMPOS, V. P.; POZZA, E. A.; NAVES, R. L.; ANDRADE JÚNIOR, W. C.; DUTRA, M. R.; COIMBRA, J. L.; MAXIMINIANO, C.; SILVA, J. R. C. Levantamento de fitonematoides em cafezais do Sul de Minas Gerais. Nematologia Brasileira, Piracicaba, v. 32, n. 1, p. 56-64, 2008.

DIAS, F. P.; CARVALHO, A. M.; MENDES, A. N. G.; VALlONE, H. S.; CARVALHO, G. R. Produção de cafeeiros Coffea arabica L. pés francos autoenxertados e enxertados em Apoatã IAC 2258. Ciência $e$ Agrotecnologia, Lavras, v. 33, n. 2, p. 484-487, 2009.

DIAS, F. P.; MENDES, A. N. G.; VALLONE, H. S.; CARVAlHO, A. M.; CARVAlHO, S. P. Desenvolvimento de cafeeiros enxertados em Apoatã IAC 2258 cultivados em recipiente de 250 litros. Ciência e Agrotecnologia, Lavras, v. 32, n. 2, p. 385-390, 2008.

FAHL, J. I.; CARRELLI, M. L. C. Estudo fisiológico da interação enxerto e porta-enxerto em plantas de café. In: CONGRESSO BRASILEIRO DE PESQUISAS CAFEEIRAS, 12., 1985, Caxambu. Resumos... Rio de Janeiro: MIC/IBC, 1985. p. 115-117.

FERREIRA, A. D.; CARVALHO, A. M.; MENDES, A. N. G.; CARVAlHO, G. R.; BOTELHO, C. E.; CARVALHO, J. G. Absorção, translocação e eficiência no uso dos macronutrientes em cafeeiros (Coffea arabica) enxertados em Apoatã IAC 2258 (Coffea canephora). Interciencia, Caracas, v. 35, n. 11, p. 1-5, 2010.
FERREIRA, A. D.; MENDES, A. N. G.; GIUIMARÃES, R. J.; CARVALHO, A. M.; PINTO, M. F. Índices fisiológicos de mudas de Coffea arabica $\mathrm{L}$. enxertadas sobre Coffea canephora. Coffee Science, Lavras, v. 4, n. 1, p. 27-34, 2009.

FERREIRA, A. D.; REZENDE, R. M.; CARVALHO, G. R.; GUIMARÃES, R. J.; FIGUEIREDO, T. F. de. Desenvolvimento vegetativo de cultivares de Coffea arabica L. enxertados em Apoatã IAC 2258 (Coffea canephora Pierre ex A. Froehner). Coffee Science, Lavras, v. 6, n. 1, p. 20-26, 2011.

FERREIRA, D. F. SISVAR: a computer statistical analysis system. Ciência e Agrotecnologia, Lavras, v. 35, n. 6, p. 1039-1042, 2011.

FIGUEIREDO, F. C.; OLIVEIRA, A. L de.; JUNIOR, W. P. de F.; GUIMARÃES, R. J.; CARVALHO, J. G.; MENDES, A. N. G. Efeito da enxertia em diferentes cultivares no desenvolvimento de mudas de cafeeiro. In: CONGRESSO BRASILEIRO DE PESQUISAS CAFEEIRAS, 28., 2002, Caxambu. Resumos... Rio de Janeiro: MIC/IBC, 2002. p. 190-192.

GUIMARÃES, R. S.; OLIVEIRA, A. L.; GUIMARÃES, R. J.; SOUZA, C. A. S.; CARVALHO, S. J. de. Efeito da enxertia no desenvolvimento de mudas de cafeeiro. In: CONGRESSO BRASILEIRO DE PESQUISAS CAFEEIRAS, 29., 2003, Araxá. Resumos... Rio de Janeiro: MIC/IBC, 2003. p. 346.

MUNIZ, M. de F. S.; CAMPOS, V. P.; CASTAGNONESERENO, P.; CASTRO, J. M. C.; ALMEIDA, M. R. A.; CARNEIRO, R. M. D. G. Diversity of Meloidogyne exígua (Tylenchida: Meloidogynidae) populations from coffee and rubber tree. Journal of Nematology, Loudonville, v. 10, n. 6, p. 897-910, 2008.

OLIVEIRA, A. L. de; GUIMARÃES, R. J.; SOUZA, C. A. S.; CARVAlHO, J. A.; MENDES, A. N. G.; GUIMARÃES, R. S. Desenvolvimento de cafeeiros (Coffea arabica L.) enxertados submetidos a diferentes níveis de reposição de água. Ciência e Agrotecnologia, Lavras, v. 28, n. 6, p. 1291-1298, 2004.

OLIVEIRA, D. S.; OLIVEIRA, R. D. L.; FREITAS, L. G.; SILVA, R. V. Variability of Meloidogyne exigua on coffee in the Zona da Mata of Minas Gerais State, Brazil. Journal of Nematology, Loudonville v. 37, n. 3, p. 323$327,2005$.

PAIVA, R. F. de; MENDES, A. N. G.; CARVALHO, G. R.; REZENDE, J. C. de; FERREIRA, A. D.; CARVALHO, A. M. de. Comportamento de cultivares de cafeeiros $C$. arabica L. enxertados sobre cultivar 'Apoatã IAC 2258' (Coffea canephora). Ciencia Rural, Santa Maria, v. 42, n. 7, p. 155-1160, 2012. 
PAULETTO, D.; MOURÃO FILHO, F. A. A.; KLUGE, R. A.; SCARPARE FILHO, J. A. Produção e vigor da videira "Niágara Rosada" relacionada com o portaenxerto. Pesquisa Agropecuária Brasileira, Brasília, v. 36, n. 1, p. 115-121, 2001.

SAS INSTITUTE. SAS/STAT software: changes and enhancements through release 6.12. Cary, 1997. $1167 \mathrm{p}$.

TOMAZ, M. A.; MARTINEZ, H. E. P.; CRUZ, C. D.; FERRARI, R. B.; ZAMBOLIM, L.; SAKIYAMA, N. S. Diferenças genéticas na eficiência de absorção, na translocação e na utilização de $\mathrm{K}, \mathrm{Ca}$ e $\mathrm{Mg}$ em mudas enxertadas de cafeeiro. Ciência Rural, Santa Maria, v. 38, n. 6, p. 1540-1546, 2008.
TOMAZ, M. A.; SAKIYAMA, N. S.; MARTINEZ, H. E. P.; CRUZ, C. D.; PEREIRA, A. A.; FREITAS, R. S. de. Porta-enxertos afetando o desenvolvimento de mudas de Coffea arabica L. Ciência Rural, Santa Maria, v. 35, n. 3, p. 570-575, 2005.

TOMAZ, M. A.; SILVA, S. R.; SAKIYAMA, S. R.; MARTINEZ, H. E. P. Eficiência de absorção, translocação e uso de cálcio, magnésio e enxofre por mudas enxertadas de Coffea arabica. Revista Brasileira de Ciência do Solo, Viçosa, v. 27, n. 5, p. 885-892, 2003.

VALLONE, H. S.; GUIMARÃES, R. J.; MENDES, A. N. G.; SOUZA, C. A. S.; CUNHA, R. L.; DIAS, F. P. Diferentes recipientes e substratos na produção de mudas de cafeeiros. Ciência e Agrotecnologia, Lavras, v. 34, n. 1, p. 55-60, 2010. 